\title{
PSIKO SPIRITUAL ISLAM \\ Sebuah Kajian Kesehatan Mental dalam Tasawuf
}

\author{
Khairunnas Rajab \\ UIN SUSKA Riau \\ Email: khairunnasrajab@gmail.com
}

\section{Abstract}

This article discusses the psycho spiritual Islam, are trying to assess the psychological framework of Islamic values which are directly related to the human psyche. This study is more focused on mysticism, as in Sufism spiritual values with more coherent and intuitive approach similar to the dimensions of psychology. Sufic itself is an al-nafs tadzkiyyah method that can bring happiness, calmness and mental health.

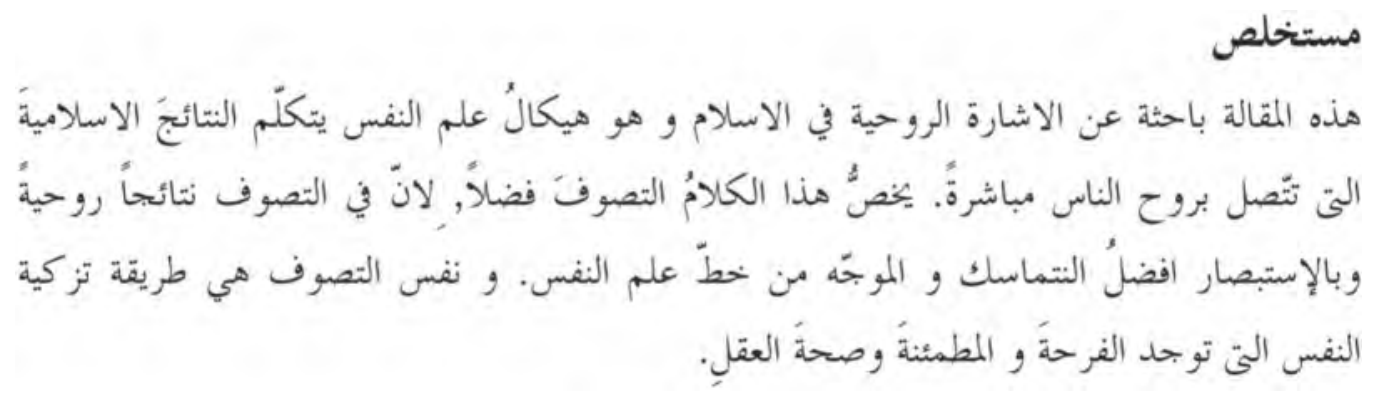

Keywords: Psikospiritual, Islam, Tasawuf

\section{A. Pendahuluan}

Manusia secara psikologi, disebut sebagai makhluk yang serba teka-teki dan rumit untuk dikenali. Dimensi psikologi manusia terasa rumit untuk dikaji disebabkan oleh kompleksnya gejala prilaku yang terdapat pada diri manusia tersebut. Al-Qur'an, mensifati manusia sebagai makhluk yang paling sempurna dan sebaikbaik bentuk. Allah berfirman yang bermaksud: 
Sungguh Kami ciptakan manusia itu sebaik-baik bentuk ${ }^{1}$

Makhluk yang mulia dibanding makhluk Allah lainnya ${ }^{2}$,

Maka diilhamkan (manusia) untuk berbuat dosa ataupun berlaku taqwa ${ }^{3}$

Manusia diberi bekal dan potensi untuk menjadi baik atau buruk sehingga dalam proses kesempurnaan diri itu, manusia berdiri sebagai subjek yang sadar dan bebas dalam menentukan pilihan baik atau buruk, jalan kebaikan atau kejahatan, berlaku taqwa atau fujr, atau jalan yang menyebabkan dirinya terpelihara atau memilih jalan kebinasaan. Dari aspek lain, al-Qur'an mensifati manusia dalam perbuatan dan kehidupannya sebagai tergesa-gesa, sebagaimana firman Allah yang bermaksud:

Dan adalah manusia itu selalu tergesa-gesa ${ }^{4}$

Sesungguhnya manusia itu menzalimi dirinya lagi ingkar (pada aturan Tuhannya) ${ }^{5}$

Sesungguhnya manusia itu diciptakan berkeluh kesah ${ }^{6}$

Adalah manusia itu dengan mudah saja bertengkar ${ }^{7}$

Dan adalah manusia itu, makhluk yang sangat dhaif dan lemah, ${ }^{8}$

Psikoterapi Islam merupakan efek emosional-psikologi yang mengkaji manusia selaku subjek pengamal agama berdasarkan dimensi iman, ibadah, akhlak dan tasawuf. Manusia dalam kaitannya dengan kesehatan mental; berusaha menjadikan dirinya tenang, tenteram dan bebas daripada gangguan mental. Kajian ini bertalian erat dengan pembentukan moral yang positif ataupun negatif. Standar penilaian bermoral itu dianggap bermarwah atau tidak adalah berdasarkan keseragaman pemahaman. Satu pemahaman menyebutkan: moral yang baik dapat diukur dengan munculnya rasa solidaritas yang tinggi, pemaaf, kesadaran untuk tidak mengganggu ketenteraman orang lain, dan menjalin hubungan yang baik dengan Allah. ${ }^{9}$ Jika basis kepada proses perkembangan psikologi adalah pertumbuhan, pembinaan dan pengembangan nilai akhlaq al-karimah yang tersentuh dalam diri dan kehidupan

QS. Al-Tin: 4

QS. Al-Isra': 70

QS. Al-Syam: 8

4 QS. Al-Isra: 11

QS. Ibrahim: 34

QS. Al-Ma'arij :19

Qs. Al-Kahfi: 54

QS. Ali Imran: 28.

9 Imam Al-Ghazali, Tahzib al-Akhlaq wa Muallajat Amradh al-Qulub, (Terj. Muhammad Baqir), (Bandung: Karisma, 1994), hal. 29-31 
manusia, maka akhlak adalah kualitas - kualitas moral yang khusus bagi manusia malahan ia merupakan basis utama kemanusiaan itu sendiri. Dalam akhlak tercermin kepribadian, di mana manusia sebagai makhluk jasmani dan rohani yang diciptakan dalam keadaan ahsan al-taqwim (sebaik-baik bentuk). Tanpa akhlak, manusia akan kehilangan azas kemanusiaannya yang akan menyebabkan ia hidup sebagai manusia tanpa kemanusiaannya atau dengan kata lain sebagai makhluk asfal safilin (makhluk yang tidak bermoral). ${ }^{10}$

Dimensi psikologi manusia, hati, roh, nafsu dan akal, memerlukan pembinaan dan pengembangan, agar selalu berada dalam salam. Ketundukan pada aturan Ilahi harus dibina agar manusia mempunyai fakultas jiwa yang bermanfaat bagi kemaslahatan hidupnya. Pembicaraan tentang hati dalam al-Qur'an sangat banyak, umpamanya, dalam firman Allah yang bermaksud:

Sesungguhnya bukanlah mata itu yang buta, buta itu adalah hati yang ada di dalam dada, ${ }^{11}$

Mereka mempunyai hati, tetapi tidak dipergunakan untuk memahami, ${ }^{12}$

Usaha Dia menjadikan apa yang dimasukkan oleh Syaitan itu sebagai cobaan bagi orang-orang yang di dalam hatinya ada penyakit dan yang kasar hatinya, ${ }^{13}$ Dalam hati mereka ada penyakit, lalu ditambah Allah penyakitnya, ${ }^{14}$

Sekali-kali tidak (demikian) sebenarnya apa yang selalu mereka usahakan itu menutup hati mereka. ${ }^{15}$

Dan Allah tidak mengunci mata hati dan pendengaran mereka dan penglihatan mereka ditutupi. ${ }^{16}$

Dan (juga) agar hati kecil orang-orang yang tidak beriman kepada kehidupan akhirat cenderung kepada bisikan itu, mereka merasa senang kepadanya dan usaha mereka mengerjakan apa yang mereka (syaitan) kerjakan. ${ }^{17}$

Yaitu pada hari harta dan anak-anak tidak berguna, kecuali orang yang menghadap Allah dengan hati yang bersih. ${ }^{18}$

10 Johan Effendi, Tasawuf Al-Qur'an Tentang Perkembangan Jiwa Manusia, dalam, Ulumul Qur'an, no. 8 Vol II, 1991, hal. 5

11 QS. Al-Hajji: 46

12 QS. Al-A'raf: 179

13 QS. Al-Hajj: 53

14 QS. Al-Baqarah: 10

15 QS. Al-Muthaffifin: 14

16 QS. Al-Baqarah: 7

17 QS. Al-An'am: 113

18 QS. Al-syura': 89 
Barang siapa yang beriman kepada Allah, maka Dia akan memberi petunjuk kepada hatinya, ${ }^{19}$

Hakikat hati telah dijelaskan dalam al-Qur'an, namun hati yang dimaksudkan di sini adalah hati yang tulus yang dapat mengerti, memahami dan mengetahui sehingga di mana ia menentukan hakikat manusia. Dalam usaha menjadikan hati itu bersih, manusia harus dibimbing menuju Allah dengan beriman dan berzikir kepada-Nya. Dalam tasawuf penyucian hati adalah hal penting; dimana proses perjalanan menuju hati yang suci perlu diterapkan dengan penuh ketekunan karena mensucikan hati akan memberi efek kepada pembinaan mental seorang muslim. ${ }^{20}$

Islam telah menetapkan dasar roh dalam diri manusia, namun hakikat roh bukanlah urusan yang mudah karena al-Qur'an membicarakan hal ini dalam firman Allah yang bermaksud:

Dan mereka bertanya kepadamu tentang roh, katakanlah, roh itu termasuk urusan Tuhanku dan tidaklah kamu diberi pengertian (ilmu) melainkan sedikit. ${ }^{21}$

Pada prinsipnya roh merupakan urusan Tuhan dan akal manusia tidak dapat menjangkau hakikat sebenarnya. Di awal penciptaan manusia, roh telah diperkenalkan Tuhan. Allah menguraikannya dalam firman-Nya yang bermaksud:

Dan ingatlah ketika Tuhanmu mengeluarkan keturunan anak-anak Adam dari sulbi mereka (seraya berkata); "Bukankah Aku ini Tuhannya"? Mereka menjawab "Betul (Engkau Tuhan kami).22

Namun roh dipengaruhi oleh sejumlah faktor yang mengelilinginya dimana faktor keluarga sangat dominan dalam mempengaruhi roh, untuk menjadikannya baik atau jahat; faktor akal fikiran yang bebas tanpa batasan akan menimbulkan keingkaran dan kesombongan dan faktor pemenuhan kebutuhan, mendesak roh berbuat spekulasi dan penyimpangan. Penyelarasan roh, agar senantiasa berada dalam "Latifah Ruhaniyyah Rabbaniyyah" memerlukan pendidikan yang seimbang sebagaimana roh yang telah mengenal Tuhannya di awal penciptaannya, dan menghiasi roh tersebut dengan amalan-amalan dan zikir kepada Allah (Tuhan).

Nafsu dalam kehidupan manusia dapat menjadi tenaga yang positif, dan kadangkala pula mendorong untuk hal-hal yang negatif. Nafsu dalam al-Qur'an dikategorikan kepada beberapa peringkat. Nafs al-ammarah yang berisi segala bentuk

19 QS. Al-Taghabun: 11

20 Sayyid Hawwa, Tarbiyah al-Ruhaniyyah, (Terj. Khairul Rafie), (Bandung: Mizan, 1998), hal. 61

21 QS. Al-Isra': 85

22 QS. Al-A'raf: 172 
perbuatan agresif dan destruktif manusia di ubah menjadi nafs al-lawwamah yang kemudiannya berubah menjadi nafs mutma'innah. ${ }^{23}$ Apabila nafsu senantiasa tunduk dan taat kepada kehendak hawa nafsu dan godaan-godaan syaitan, ia dinamakan alnafs al-ammarah bi al-su' (nafsu yang menyerah pada kejahatan). Allah berfirman yang bermaksud:

Dan Aku tidak membebaskan diriku daripada kesalahan, karena sesungguhnya nafsu itu selalu menyerah kepada kejahatan. ${ }^{24}$

Bila ketenangan nafsu itu belum sempurna, namun tetap menyerah dan membuka peluang kepada hawa nafsu, maka nafsu yang demikian disebut al-nafs al-lawwamah (jiwa yang menyesali dirinya sendiri). Kemudiannya nafsu itu mencerca pemiliknya ketika dia lalai dari melakukan pengabdian kepada Tuhannya. Allah mengingatkan dalam firman-Nya yang bermaksud:

Dan Aku bersumpah dengan jiwa yang amat menyesali (dirinya sendiri). ${ }^{25}$

Namun apabila nafsu tenang berada di bawah perintah Allah dan ia meninggalkan semua perkara syahwat maka ia disebut al-nafs al- mutma'innah (jiwa yang tenteram) ${ }^{26}$ Allah memanggil jiwa yang tenang ini dengan sebutan, dalam firman-Nya yang bermaksud:

Hai jiwa yang tenteram, kembalilah kepada Tuhanmu dengan hati puas lagi diredhaiNya. ${ }^{27}$

Akal dalam dimensi kemanusiaan berperanan penting untuk mempertanggung jawabkan perbuatannya di hadapan Allah. Akal sebagaimana roh dan nafsu juga memiliki kecenderungan untuk melakukan kebaikan dan keburukan. Namun, akal yang diberi taklif adalah akal rasional atau akal rendah yang menentang kodratnya sebagai manusia.

Empat dimensi psikis manusia; hati, roh, nafsu dan akal memiliki potensi pembinaan dan pengembangan mental dan moral menuju akhlaq al-karimah yang sesuai dengan kodrat azalinya yang dibawa semenjak lahir. Tasawuf melihat pribadi manusia sebagai sesuatu yang unik membutuhkan pembinaan dan pengembangan untuk menjadi insan yang mengenali, mengabdi dan mendekati diri kepada Allah. Dengan cara itu seorang sufi dapat mencapai spritual yang tinggi, meraih

23 Johan Effendi, Tasawuf Al-Qur'an..., hal. 21

24 QS. Yusuf: 53

25 QS. Al-Qiyamah: 2

26 Sayyid Hawwa, Tarbiyah al-Ruhaniyyah..., hal. 46

27 QS. Al-Fajr: 28 
kesempurnaan dan kesucian rohaniah yang murni. Usaha sedemikian disebut oleh kaum sufi dengan tadhkiyyah al-nafs yaitu proses perkembangan psikologi manusia, menuju kondisi batiniah yang meraih al-falah (kesempurnaan), al-najat (kejayaan) dan mutma’innah (ketenangan).

Kemenangan, kejayaan, ketenangan atau dalam bahasa yang agak umum kebahagiaan (happiness - al-sa'adah: Arab) sebenarnya adalah kumpulan ketenangan mental dalam satu kesatuan pribadi yang utuh. ${ }^{28}$ Dan ketenangan mental (mutma'innah) dapat diperoleh dengan mengingat Allah dan beramal saleh. Allah berfirman yang bermaksud:

Ketahuilah! Hanya dengan mengingat Allah hati menjadi tenang. ${ }^{29}$

Ketenangan jiwa ataupun kebahagiaan hidup tidak dapat diraih tanpa menghilangkan gangguan-gangguan yang berkemungkinan menghambat proses tadhkiyyah al-nafs berlangsung. Gangguan itu biasanya lahir daripada sikap rasa berdosa, bersalah atau rasa dendam. ${ }^{30}$ Islam menyarankan umatnya supaya tidak terlalu memikirkan tentang dosa. ${ }^{31}$ Ini adalah karena, secara psikologi orang yang berbuat dosa akan merasa gelisah dan cemas selama rasa berdosa itu berada dalam dirinya. ${ }^{32}$

Dalam psikoterapi sufistik, pengajaran dan bimbingan rohani menuju Allah SWT, adalah suatu proses yang berterusan. Sebelum seorang sufi menyibukkan dirinya dengan ibadah, dia harus melalui proses yang disebutnya dengan maqamat (it station) dan al-ahwal. Proses perjalanan sufi tersebut adalah melalui taqarrub dan zikkrullah yang akan menaikkannya ke puncak ma'rifatullah untuk mencapai tahap kebahagiaan dan mendekatkan diri kepada Allah SWT.

\section{B. Maqam Taubat dalam Kesehatan Mental}

Daripada terminologi taubat tersimpan makna esoterik di mana seseorang Salik bangun daripada sadarnya, ${ }^{33}$ menyadari sepenuhnya atas perbuatan tidak

28 Zakiah Darajat Kebahagiaan, (Jakarta: Ruhama, 1988), hal. 13

29 QS. Al-Ra'd: 29

30 Zakiah Darajat, Puasa Meningkatkan Kesihatan Mental, (Jakarta: Ruhama, 1989), hal. 18

31 Sayyid Hashim Al-Rasuli al-Mahallati, Iqaba al-Dhunub, (Terj. Bahruddin Fanani), (Bandung: Pustaka Hidayah, 1994), hal. 43

32 Yahya Jaya, Peranan Taubat dan Maaf dalam Kesihatan Mental, (Jakarta: Ruhama, 1992), hal. 58.

Taubat adalah usaha menyucikan jiwa dan melegakan fikiran manusia daripada beban dosa dan kesalahan. Ahmad masri dan Nadhif Jama' Adam, The Way to Happiness, (Terj. Muhammad hashim), (Jakarta: Lentera, 1996), hal. 98 
baik yang dilakukannya. Usaha kesadaran daripada dosa dan kesalahan, mendorongnya untuk berlaku baik dan beramal saleh. Dalam tasawuf, cara seperti ini, harus dilalui dengan benar dan ikhlas. Seorang salik harus benar-benar memahami dirinya sebagai berdosa karena itu dia menyesalinya dengan taubat yang murni (taubat nasuha), sehingga rasa berdosanya terkikis habis daripada psikologinya. Proses taubat ini sebenarnya adalah usaha Takhalli ${ }^{34}$ (pengosongan diri daripada nilai-nilai kejahatan). Dalam Islam, Penyembuhan jiwa daripada rasa berdosa dan bersalah; adalah melalui pintu taubat dengan sebenar-benarnya karena dengan dosa itu, seseorang itu akan senantiasa cemas dan tegang. ${ }^{35}$

Taubat itu sendiri mengandung makna "kembali"; dia bertaubat, berarti dia kembali. Jadi taubat adalah kembali dari sesuatu yang dicela oleh syara' menuju sesuatu yang dipuji olehnya. ${ }^{36}$ Al-Junaid al-Baghdadi, seorang ahli sufi ${ }^{37}$ pernah ditanya tentang taubat. Dia menjawab: "Taubat adalah penghapusan dosa seseorang." Pertanyaan yang sama juga diajukan kepada Sahl al-Tustani, seorang ahli sufi katanya: "Taubat berarti tidak melupakan dosa seseorang". ${ }^{38}$ Taubat menurut Ibn al-Qayyim al-Jauziyyah adalah "kembalinya seorang hamba kepada Allah dengan meninggalkan jalan orang-orang yang dimurkai Tuhan dan jalan orang-orang yang tersesat. Dia tidak mudah memperolehnya kecuali dengan hidayah Allah agar dia mengikuti sirat al-Mustaqim (jalan yang lurus)" ${ }^{39}$ Taubat itu sendiri tidak sah kecuali dengan menyadari dosa tersebut, mengakui dan berusaha mengatasi akibat-akibat dari dosa yang dilakukan. Menurut pengertian lain taubat juga berarti "bangunnya jiwa manusia yang melahirkan kesadaran terhadap segala kekurangan atau kesalahannya dan menetapkan tekad dan azam yang disertai dengan amal perbuatan untuk memperbaikinya". ${ }^{40}$

34 Takhalli adalah mengosongkan diri daripada fujr (dosa) dan sifat buruk yang terdapat dalam diri, Proyek Pembinaan PTA, Pengantar Ilmu Tasawuf, (Sumut: IAIN, 1981), hal. 99

35 Al-Mahallati, Iqaba al-Dhunub..., hal. 44

36 Imam al-Qusyairi al-Naisaburi, Al-Risalah Qusyairiyah, (terj. Lukman Hakim), (Surabaya: Risalah Gusti, 1999), hal.79

37 Ali Ibn Utsman al-Hujwiri, The Kasyful Mahjub: the Oldest Persian Treatist and Sufi, Terj. Suwarjo Matori, (Bandung: Mizan, 1993), hal. 124

38 Ibn Abi Ishaq Muhammad Ibn Ibrahim Ya'kub al-Bukhari al-Kalabadzi, al-Ta'arruf li Madhhab Ahl al-Tasawuf, (Terj. Rahmani Astuti), (Bandung: Mizan, 1998), hal.124

39 Ibn Al-Qayyim al-Jauziyyah, Madarij al-Salikin Bain Manazil Iyyaka Na’bud wa Iyyaka Nasta’in, (Terj. Kathur Sukardi), (Jakarta: Pustaka Al-Kautsar, 1998), hal. 97

40 M. Chatib Quzwain, Mengenal Allah: Suatu Pengajian Mengenai Ajaran Tasawuf Syaikh Abdul Samad Al-Palimbani, (Jakarta: Bulan Bintang, 1990) hal. 79 
Dalam tasawuf, seorang salik diajarkan bertaubat supaya dia mendekatkan dirinya kepada Allah SWT. Pengakuannya terhadap dosa dan kesalahan adalah usaha permulaan dalam memahami dirinya yang kemudian secara bertahap dia akan mengenal Tuhannya. Proses ini di dalam psikoterapi dan kesehatan mental merupakan perawatan (curative), pencegahan (preventive) dan pembinaan (constructive).

Apabila taubat merupakan pengakuan dosa dan penyesalan diri, maka orang yang menderita dapat mengungkapkan perasaan berdosa dan bersalahnya kepada Allah SWT. serta menyadari dan memperbaiki dosanya. Dengan bertaubat, seseorang akan memperolehi kelegaan batin karena dia merasa pengakuan dosa dan penyesalannya didengar, diperhatikan dan diterima oleh Allah SWT, serta memperoleh keampunan dan kasih sayang dari-Nya. Taubat yang murni dengan meyakini sifat Allah SWT yang Maha Penerima Taubat, Pengampun dan Penyayang, akan membuatkan seseorang itu sehat mentalnya dan menjadikan taubat sebagai metode terapeutik (pengobatan). ${ }^{41}$

Taubat yang diimbangi dengan amalan-amalan baik, ${ }^{42}$ akan membebaskan seorang salik daripada kegelisahan dan kecemasan yang terdapat dalam dirinya. Amal saleh setelah taubat dalam psikoterapi sufistik, disebut juga dengan Tajalli ${ }^{43}$ (anugerah Ilahi atas penerimaan taubatnya dan mengisinya dengan ubudiyah dan amal saleh) yang secara psikologi dikenali dengan proses pencegahan (preventive)

Setiap kali seseorang salik bertaqarrub (mendekatkan diri) dengan Allah SWT, sedemikian pula dia membina dirinya, tetap dalam kesehatan mental dan kelegaan batin. Tingkat pembinaan (konstruksi) ini, di dalam tasawuf disebut dengan Tahalli ${ }^{24}$ (menghiasi dirinya dengan amalan-amalan saleh).

Dalam psikoterapi taubat, seorang terapis mendorong individu agar senantiasa menghiasi diri dengan ibadah dan amal saleh. Perlakuan semacam ini, merupakan usaha terapis dalam membina pasien dalam ketaqwaan dan keimanan yang kuat. Terapis mendorong individu tersebut dalam ketaatan dan tidak memikirkan untuk berbuat dan memikirkan tentang dosa dan maksiat yang dilakukannya pada masa lampau.

41 Yahya Jaya, Spiritualisasi..., hal.123

42 Taubat sebenarnya merupakan imbangan manusia daripada rahmat Tuhannya yang tidak dapat diduga, Toshihiko Izutsu, Ethico Religious Concept in the Qur'an, (Canada: Mc Gill University, 1966), hal.174

43 Tajalli adalah anugerah yang kemudian terjadi pengisian jiwa yang kosong daripada cela dan dosa dengan nilai-nilai agama, di mana seorang individu mengimbangi perbuatan dosanya dengan amalan saleh dan akhlak mahmudah. Proyek Pembinaan PTA, Pengantar Ilmu Tasawuf.., hal.110

44 Tahalli iaitu menghiasi diri dengan nilai-nilai syari'at dan kemuliaan akhlak, Ibid. 


\section{Maqam Zuhud dalam Kesehatan Mental}

Secara terminologi zuhud adalah mengarahkan keinginan kepada Allah SWT, menyatukan kemauan kepada-Nya dan sibuk dengan-Nya dan meninggalkan kesibukankesibukan lainnya dengan harapan, agar Allah memperhatikan dan membimbing seorang zahid (orang yang berprilaku zuhud). ${ }^{45}$ Al-Junaid al-Baghdadi mengatakan : "Zuhud" adalah "ketika tangan tidak memiliki apa-apa pun dan pengosongan hati dari cita-cita". Di sini seorang sufi tidak memiliki sesuatu yang berharga melainkan Tuhan yang dirasakannya dekat dengan diriya. Sebagaimana juga Yahya ibn Muadz menyatakan bahwa zuhud adalah meninggalkan apa yang mudah ditinggalkan. ${ }^{46}$

Seorang sufi meninggalkan harta benda dan kemewahan duniawi untuk menuju Tuhan yang dicintai. Menurut imam al-Ghazali hakikat zuhud itu adalah meninggalkan sesuatu yang dikasihi dan berpaling darinya kepada sesuatu yang lain, yang terlebih baik darinya karena menginginkan sesuatu di dalam akhirat, dikatakan zuhud. ${ }^{47}$ Seiring dengan pernyataan Imam al-Ghazali, Ibn Taimiyyah juga berkata bahwa zuhud itu berarti meninggalkan apa-apa yang tidak bermanfaat untuk kepentingan akhirat. ${ }^{48}$

Meninggalkan sesuatu yang dicintai dengan mengejar sesuatu lain yang lebih baik adalah tujuan penting seorang zahid. Bagi zahid tidak ada yang lebih dicintai, kecuali Allah SWT yaitu dengan memburu kehidupan yang lebih baik (akhirat) dengan mencintai Allah SWT dan mengharapkan keredhaan-Nya.

Hidup sebagai seorang zahid menuntut psikologi kepada kebahagiaan hakiki yaitu mereka mengutamakan kehidupan akhirat yang lebih kekal dan nikmat. Sifat zuhud ini sangat besar fungsinya dalam mencapai kemenangan (al-falah), kejayaan (an-najah) dan kebahagiaan (al-sa'adah). Dalam menjalani kehidupan sebagai seorang zahid, ia berusaha memenuhi kebutuhannya dengan mendekatkan diri kepada Allah SWT serta menangguhkan keperluan lainnya ${ }^{49}$ untuk mencapai spritual yang tinggi.

Psikoterapi zuhud dapat berfungsi sebagai metode takhalli (pengosongan), tajalli (anugerah dan pengisian) dan tahalli (penghiasan). Rawatan atas gangguan kejiwaan dengan menggunakan langkah tajalli bererti mengamalkan aturan-aturan

45 Ibn al-Qayyim al-Jauziyyah, Thariq al-Hijratain, (terj. Kathur Sukardi), (Jakarta: Pustaka al-Kautsar, 1998), hal.307

46 Al-Kalabadzi, Op. Cit., hal.115

47 Qassim al-Halabi, al-Sair wa al-Suluk Ila Malik al-Muluk, Jakarta, Naskah Perpustakaan Nasional (Musium Pusat), No.CCCTX IV, hal.88

48 Ibn al-Qayyim, Madarij, Op.cit., hal.148

49 Kecintaan kepada dunia, memperolehi harta, dan kemahuan biologinya 
Ilahi dan menghindarkan diri kepada kehendak-kehendak-Nya karena mengharapkan kerelaan Allah SWT. Dengan demikian, metode tahalli merupakan langkah yang efektif bagi perawatan gangguan mental, kecemasan dan ketidaksehatan mental. Sikap zuhud adalah penghindaran diri daripada sifat tamak ${ }^{50}$ (rakus) dan kecintaan terhadap dunia ${ }^{51}$ (hub-al-dunya) yang berlebihan.

Mental seorang yang zahid bebas daripada kedua-dua sifat di atas itu akan mendatangkan kelegaan, ketenangan dan kesehatan mental. Dalam fungsi takhalli psikoterapi zuhud bermakna pencegahan (preventive) daripada tergelincir pada sifat negatif sifat seperti di atas tersebut sehingga melahirkan keseimbangan dan integritas yang tinggi, pada diri seseorang. Sementara itu, dalam fungsi tahalli (penghiasan diri), psikoterapi zuhud berperanan dalam mempertahankan keadaan yang tetap dalam kesehatan mental dan ketenangan jiwa.

Pada Komponen psikoterapi zuhud, seorang terapis berfungsi sebagai motivator kepada pasien. Seorang terapis membina pasien agar senantiasa dalam kehidupan yang sederhana dan tidak berlebihan.

\section{Maqam Sabar dan Tawakkal dalam Kesehatan Mental}

Sabar bukanlah sesuatu yang harus diterima seadanya, bahkan sabar adalah upaya kesungguhan yang juga merupakan sifat tuhan yang sangat mulia dan tinggi. Sabar ialah menahan diri dalam memikul sesuatu penderitan, baik dalam sesuatu perkara yang tidak diingini maupun dalam kehilangan sesuatu yang disenangi. ${ }^{52}$ Menurut Imam Ahmad ibn Hanbal, perkataan sabar disebut dalam al-Qur'an di tujuh puluh tempat. Menurut ijma' ulama, sabar ini wajib dan merupakan sebagian dari syukur. ${ }^{53}$ Sabar dalam pengertian lughawi (bahasa) adalah "menahan atau bertahan". Jadi sabar sendiri adalah "menahan diri dari rasa gelisah, cemas dan marah, menahan lidah dari keluh kesah serta menahan anggota tubuh dari kekacauan". ${ }^{54}$

50 Tamak adalah factor yang membawa kesengsaraan dalam kehidupan manusia, lihat Sayyid Mujtaba Musavi Lari, (1990), Youth and Moral, Quin, Islamic Culture Development Office, hal.145

51 Penyakit ini boleh disembuhkan dengan merenungkan bahawa segala kenikmatan duniawi adalah fana' dan yang kekal pada manusia adalah pencapaian jiwa, dekat dengan Allah dan usahausaha yang dilakukan bagi kepentingan akhirat, Lihat Muhammad Mahdi Ibn Abi Zar An-Naraqy, (1993), Jami’ Al-Sa’adah, (Terj. M. Hasim), Bandung, Mizan, hal. 87

52 M. Khatib Quzwain, Op.Cit., hal.90

53 Ibn al-Qayyim al-Jauziyyah, Madarij, Op.Cit., hal.203

54 Ibid., hal.26 
Sabar juga merupakan sikap jiwa yang ditampilkan dalam peneriman sesuatu, baik berkenaan dengan penerimaan tugas dalam bentuk suruhan dan larangan, maupun dalam bentuk perlakuan terhadap orang lain, serta sikap menghadapi sesuatu musibah..$^{55}$ Sabar merupakan sifat yang secara holistik harus dimiliki oleh seorang sufi. Sabar sendiri tidak mengenal bentuk ancaman dan ujian; seorang sufi semestinya berada dalam ketabahan dan kesabaran yang utuh.

Tawakkal adalah kepercayaan dan penyerahan diri kepada takdir Allah dengan sepenuh jiwa dan raga. Dalam tasawuf, tawakkal ditafsirkan sebagai suatu keadaan jiwa yang tetap berada selamanya dalam ketenangan dan ketenteraman, baik dalam keadaan suka maupun duka. Dalam keadaan suka cita, akan bersyukur dan dalam keadaan duka, akan bersabar serta tidak resah dan gelisah. ${ }^{56}$ Sari al-Saqati ${ }^{57}$ mengatakan : "Tawakkal adalah pelepasan dari kekuasaan dan kekuatan, tidak ada kekuasaan dan kekuatan apapun melainkan dari Allah semesta Alam. ${ }^{58}$

Sabar dan tawakkal adalah dua sifat yang utama dan terpuji. Kedua-duanya merupakan sifat Tuhan yang baik untuk disifati oleh manusia. Sabar adalah sikap mental dalam menerima sesuatu perkara baik ataupun buruk bagi dirinya. Sementara tawakkal adalah sikap jiwa dengan menyerahkan diri kepada takdir Ilahi. ${ }^{59}$ Dalam suka maupun duka dengan kesan bahwa Tuhan dipercayai sebagai tempat berdoa dan bermunajat. Seorang sufi yang menjalani kehidupan rohani akan berusaha dengan semaksimal mungkin dan dengan harapan mendapat hasil yang maksimal juga.

Sabar dan tawakkal harus didasarkan atas iman yang kuat, karena tanpa keimanan, kesabaran akan mudah pupus, demikian juga dengan tawakkal akan jatuh ke dalam kebimbangan. Sabar maupun tawakkal, kedua-duanya menjadi perisai

55 KHAL. Muslim Nurdin, (1993), Moral dan Kognisi Islam, Bandung, al-Fabeta, hal. 239

56 Yahya Jaya, (1994), Spiritualisasi Islam Dalam Menumbuhkembangkan Kepribadian dan Kesehatan Mental, Jakarta, Ruhama, hal. 169

57 Lihat Imam Al-Qusyairy, Risalah Qusyairiyyah, Op.Cit., , hal. 519

58 Al-Kalabadzi, Op.Cit, hal.125

59 Sifat-sifat manusia diturunkan daripada atau dibatasi di dalam sifat Tuhan, dan manusia tidak memiliki gagasan tentang sifat Tuhan yang terbatas. Yang terbatas tentu saja tidak boleh melingkupi yang tidak terbatas, dan kehendak manusia kerana merupakan turunan daripada kehendak Tuhan. Kehendak Tuhan adalah bebas, maka pada manusia sejauh identik dengan Tuhan, juga akan bebas sekaligus juga terbatas kerana sifat-Nya yang lain adalah terbatas dan memiliki kesementaraan (temporal) dan kemudian menjadi takdir yang ditetapkan. Lihat, Khan Salib Khaja, (1987), Studies In Tasawuf, (Terj. Ahmad Nasir), Jakarta, Rajawali Pers, hal. 153 
bagi perjalanan hidup seorang sufi. Dengan bantuan iman yang kuat, kedua-duanya boleh mendekatkan seorang sufi pada Tuhannya.

Dalam psikoterapi sufistik, sabar dan tawakkal dapat berfungsi sebagai tajalli, tahalli dan takhalli. Sifat sabar dan tawakkal dapat berfungsi sebagai tajalli karena dengannya seorang sufi telah mewujudkan perasaan tenteram dan tenang dan tidak mudah gelisah serta cemas jika ditimpa musibah dan ujian, lebih-lebih lagi jika ia bertawakkal pada Tuhannya. Oleh itu metode tajalli ini, sabar yang bertalian dengan sifat tawakkal adalah usaha pengobatan daripada gangguan kekejiwaan dan ketidak seimbangan mental. Melalui metode tahalli, seorang sufi menghiasi dirinya dengan sifat sabar dan tawakkal, yang dapat melahirkan kesehatan mental dan kelegaan batin. Pada tahap metode takhalli, seorang sufi dengan kesabaran dan ketawakkalannya dapat menghindarkan dirinya daripada kemungkinan jatuh pada hal yang buruk dan metode ini berfungsi sebagai asas untuk tetap dalam sabar dan tawakkal.

Komponen sabar dan tawakkal digunakan sebagai metode oleh para terapis secara berkesinambungan. Terapis memberikan arahan dan panduan kepada individu, agar senantiasa sabar dalam menghadapi musibah dan menyerahkan segala keputusan kepada takdir Allah. Seorang pasien yang dapat mengamalkan ajaran tentang kesabaran dan tawakkal dapat menjadikan kehidupan yang lebih tenang dan tenteram, karena adanya keyakinan bahwa semua yang menimpanya adalah ketentuan daripada Allah SWT.

\section{E. Anugerah Redha dalam Kesehatan Mental}

Bagi Imam al-Ghazali kelebihan redha Allah SWT merupakan manifestasi dari keredhaan hamba. ${ }^{60}$ Redha terikat dengan nilai penyerahan diri kepada Tuhan yang bergantung kepada usaha manusia dalam berhubungan dengan Tuhannya, agar senantiasa dekat dengan Tuhannya. Syeikh Abu Ali al-Daqqaq menyatakan bahwa seorang sufi tidak merasa terbebani dengan hukum dan qadar Allah Ta'ala. ${ }^{61}$

Bagi Imam al-Ghazali kelebihan redha Allah SWT merupakan manifestasi dari keredhaan hamba. ${ }^{62}$ Redha terikat dengan nilai penyerahan diri kepada

60 Imam al-Ghazali, (1996), Al-Mukasyafat al-Qulub, (Terj. Ahmad Sunarji), Bandung, Husaini, hal. 346

61 Imam Al-Qusyairy, Op.Cit.., hal.223

62 Imam al-Ghazali, (1996), Al-Mukasyafat al-Qulub, (Terj. Ahmad Sunarji), Bandung, Husaini, hal. 346 
Tuhan yang bergantung kepada usaha manusia dalam berhubungan dengan Tuhannya, agar senantiasa dekat dengan Tuhannya. Syeikh Abu Ali al-Daqqaq menyatakan bahwa seorang sufi tidak merasa terbebani dengan hukum dan qadar Allah Ta'ala. ${ }^{63}$

Redha merupakan puncak kecintaan yang lahir daripada pengabdian yang sungguh-sungguh dan penuh kepasrahan, tawaddu'dan tawakkal. Kesanggupan seorang sufi dalam menanggung cobaan dan ujian dapat meningkatkan stabilitas keredhaan dan tetap terpahat dalam dirinya. Keadaan stabil yang ditimbulkan oleh sifat redha, adalah sifat manifestasi pada ketinggian agama, ketinggian pengabdian, dan kekhusyu'an dalam bertaqarrub kepada Allah SWT. Dalam psikoterapi sufistik, redha dapat menjadi tenaga inovatif, sumber integritas dan kekuatan dalam spritualitas. Apabila redha dapat berfungsi secara inovatif, berintegritas dan kekuatan dalam spiritual, maka redha berlaku bagi takhalliyah al-nafs, tajalli al-nafs, dan tahalliyah al-nafs. Ketiga-tiga fungsi ini dalam psikoterapi sufistik bersesuaian dengan metode kesehatan mental dan redha adalah metode pencegahan (preventive), pengobatan (curative) dan pembinaan (constructive).

Apabila fungsi takhalliyah al-Nafs dan tahalliyah al-nafs menguasai diri seorang sufi, maka redha dapat mewujudkan kebahagiaan, kelestarian, keserasian dan kesehatan mental. Oleh itu, keredhaan dengan muatan yang dikandungnya adalah usaha menghilangkan persepsi buruk terhadap Tuhan dan menukarnya dengan keyakinan bahwa sesuatu yang ditimpakan oleh Allah SWT pada seorang 'abid (hamba) mempunyai hikmah yang dalam dan hanya diketahui oleh sebagian orang yang dikehendaki Ilahi.

Dalam amalan terapi, seorang terapis dapat mempraktekkan metodologi psikoterapi redha kepada pasien, supaya dia senantiasa mencari keredhaan Allah SWT yaitu dengan melakukan ketaatan dan ketaqwaan. Melalui proses ini, seorang pasien membiasakan dirinya dalam keredhaan dan berusaha untuk mencapai keredhaan Allah SWT.

\section{F. Anugerah Mahabbah dan Ma'rifah dalam Kesehatan Mental}

Mahabbah dan ma'rifah adalah dua sifat dalam tingkat tasawuf. Mahabbah dan ma'rifah menduduki posisi yang tinggi di antara sekian maqam dan ahwal (peringkat) dalam sufisme. Dengan mahabbah dan ma'rifah seorang sufi mempunyai

${ }^{63}$ Imam Al-Qusyairy, Op.Cit.., hal.223 
ikatan yang kuat dengan Tuhannya, melalui ibadah dan muatan cinta kepada Ilahi, sehingga mencapai tahap ma'rifah (Tuhan). ${ }^{64}$ Hubb Ilahi (cinta kepada Tuhan) mendorong seorang sufi untuk beramal dan berkorban untuk meraih cinta, dan dia berada dalam keasyikan (asyiq-masyuq) bercinta dengan Tuhannya, sehingga ia lupa daripada perkara yang lain. Ma'rifah pada prinsipnya adalah intuisi bawah kesadaran manusia yang diperolehnya daripada ketajaman mata hati setelah menjalani masa yang panjang dengan latihan-latihan rohaniah sehingga Allah SWT melimpahkan anugerah ma'rifah-Nya kepada orang yang berusaha secara maksimal untuk mendekati Tuhannya. ${ }^{65}$

Seorang sufi yang asyik dalam cinta Ilahi, akan memperoleh kebahagiaan, ketenangan dan kemenangan. Sebaliknya jika cinta Ilahi itu menjadi kurang dan hilang, dia dapat kembali ke dalam kegersangan dan patah hati. Demikian juga dengan ma'rifatullah yang membolehkan seorang sufi merasakan dirinya melihat Tuhannya dan dia meyakini bahwa Tuhannya selalu memimpin perjalanan hidupnya. Perasaan anugerah ma'rifah dalam diri sufi melahirkan kondisi batiniah yang tenang, damai dan tenteram.

Dalam klinik sufi, mahabbah dan ma'rifah adalah tenaga inovatif dan progresif, yang dapat berfungsi secara tahalli, tajalli dan takhalli. Mahabbah dan ma'rifah akan menghiasi sufi dengan muatan cinta Ilahi dan anugerah ma'rifah yang pada hakikatnya telah memberi makna yang sejati dalam hidup sufi. Tahap tahalli ini dalam psikoterapi sufistik disebut pembinaan psikologi kepada posisi yang lebih baik. Fungsi tajalli dalam mahabbah dan ma'rifah tercemar oleh nilai tahalli, karena hakikat tahalli yang terdapat pada mahabbah dan ma'rifah dengan sendirinya berperanan aktif menjaga seorang sufi selalu dalam cinta yang asyik dan anugerah ma'rifah. Dengan demikian, tahalli mahabbah dan ma'rifah berfungsi mengobati jiwa seorang pasien. Pada aspek takhalli seorang sufi bebas daripada sifat tidak baik yang berkemungkinan menghilangkan rasa ketenteraman dan kesehatan mental sufi. Apabila fungsi takhalli digunakan untuk mengobati gangguan mental maka dia berlaku sebagai pencegahan.

Mahabbah dan ma'rifah tidak diperoleh oleh individu tanpa ibadah yang khusyu' dan amalan zikir yang kontinuitas. Karena itu, seorang terapis selalunya

64 Syekh Muhammad Mahdi al-Syafi, (1996), Al-hubb Ilahi fi Adliyyah Ahl Bait, (Terj. Ikhlas), Bandung, Pustaka Hidayah, hal. 13

65 Samih 'Atif al-Zain, (1993), al-Syufiyyah fi Nazri al-Islam, Beirut, Maktabah al-Diratsah, hal. 405 
memberikan motivasi kepada pasien supaya senantiasa meningkatkan ibadah melalui amalan zikir dan bertaqarrub kepada Allah SWT. Seorang pasien yang menunaikan tugas yang diberikan oleh terapis dapat secara berangsuran merasai dalam ketenangan dan kesehatan mental.

\section{G. Anugerah Psikoterapi Khauf dan Tawaddhu’dalam Kesehatan Mental}

Khauf dan tawaddhu' merupakan dua sifat positif yang diperoleh oleh kaum sufi dan merupakan rahmat daripada Allah SWT. Kedua-duanya menjadi inti daripada kepribadian manusia. Perasaan khauf (takut) kepada Allah SWT yang memiliki oleh sufi melebihi segalanya. Dia merasa khawatir atas amalannya diterima atau tidak. Lebih daripada itu, khauf adalah tempat persinggahan hati dan menjadi pengawal hati menuju Tuhan-Nya. Hasrat dan fikiran negatif dapat dibuang dalam menuju kebaikan dan aturan Ilahi. Perasaan Tawaddhu' (rendah hati) yang hadir dari sanubari seorang sufi mengalahkan kesombongan dan keangkuhan yang muncul daripada nafs syaitanniyyah. Tawaddhu' sendiri adalah merupakan ketundukan terhadap kebenaran dan kekuasaan Allah SWT. Seorang sufi yang lari dari sifat tercela, seperti kembali pada ketawadhu'annya sehingga akan melahirkan integrasi diri, kelegaan dan ketenteraman.

Sifat khauf ataupun tawadhu' (kerendahan hati) secara metodis dapat membentuk psikologi insaniah yang baik dan terpuji. Kehadiran dua sifat utama tersebut dan tinggal dalam diri seorang sufi, dapat membentuknya menjadi seorang terhormat dimata zahir manusia dan dekat dengan Tuhannya.

Apabila sifat khauf dan tawadhu' melekat erat pada diri seorang sufi maka kedua-duanya dapat berfungsi takhalli, tajalli, dan tahalli yang membentuk metode pencegahan (preventive), pengobatan (curative) dan pembinaan (constructive).

Fungsi terapi khauf dan tawadhu' dalam takhalli adalah mengenepikan sifatsifat yang berlawanan dengan kedua-duanya. Pupusnya sifat tercela angkuh dan sombong pada diri sufi dan kembali kepada fungsi tajall; mengisinya dengan sifat khauf dan tawadhu'akan mewujudkan rasa ketenangan, ketenteraman dan kebahagiaan dalam dirinya. Dalam menjalin fungsi tahalli, seorang sufi dengan khauf dan tawadhu'nya serta menjaga kondisinya yang baik dan positif, merupakan pembinaan yang dapat direalisasikan dengan amal saleh dan melakukan amalan-amalan utama dan baik (Fadha'il al-'amal). Proses terapi dalam hal ini menjadikan pasien itu senantiasa dalam khauf dan tawadhu' dalam menjalani hidup sehariannya. 


\section{H. Anugerah Taqwa dan Ikhlas dalam Kesehatan Mental}

Bertaqwa dan berlaku ikhlas dalam kehidupan dapat menghindari diri daripada sifat buruk yang dapat menghalang manusia, mensifati sifat taqwa dan ikhlas, membolehkan seseorang sampai kepada darjat yang utama dan tinggi dalam Islam. Taqwa yang secara sederhana mengandung makna pelaksanaan perintah, menghentikan larangan dan imbangan perilaku teladan dan terpuji. ${ }^{66}$ Taqwa juga dapat mendorong (memotivasi) seseorang untuk memelihara dirinya daripada celaan dan siksaan batin. Seorang mukhlis (orang yang berlaku ikhlas) mendambakan dirinya kepada Allah SWT melalui aktivitas dan amalan yang bersih daripada nilai riya'. Keikhlasan bukanlah pengembangan monotonisme dan statisme dalam diri, tetapi ia adalah sesuatu yang dinamis yang menuntut kesungguhan pemeliharaan dan peningkatan. ${ }^{67}$

Jadi taqwa maupun ikhlas adalah dua sifat yang sangat erat kaitannya dengan pencegahan (preventive), perawatan (curative) dan pembinaan (constructive). Dalam psikoterapi sufistik maupun kesehatan mental; taqwa dan ikhlas dapat berfungsi dalam metode takhalli, tajalli dan tahalli. Melalui fungsi takhalli, seorang sufi dapat menyingkirkan kekurangan, keburukan dan kerusakan moral dengan mengisinya (tajalliyyah al-nafs) dengan sifat taqwa dan ikhlas sehingga mereka berada dalam pemeliharaan diri (tahalliyyah al-nafs) untuk tetap berada dalam keadaan yang positif. Sikap taqwa dan ikhlas yang untuk seperti ini dalam psikoterapi sufistik akan teraplikasi kewujudan kebahagiaan, ketenangan dan kesehatan mental. Semakin kuat melekat rasa ketaqwaan dan keikhlasan pada seorang sufi, semakin longgar pula makna hidup (the meaningfull life) dan kesehatan mental dapat diraih.

Ketaqwaan dan keikhlasan merupakan prinsip asasi dalam tasawuf. Seorang terapis memotivasi pasien supaya senantiasa bertaqwa dan berlaku ikhlas dalam beramal tanpa dicampuri oleh rasa riya'. Dengan demikian, seorang pasien, insyaalah secara bertahap memasuki ketenangan dan kesehatan mental.

\section{Anugerah Syukur dan Mutma'innah dalam Kesehatan Mental}

Dalam spiritual Islam, syukur dan mutma'innah merupakan kebangkitan moral, menjadi insan berpotensi dan utuh. Syukur dan mutma'innah adalah dua sifat yang dapat mengembangkan psikologi al-Qur'an pada setiap

66 Zakiah Darajat, Puasa, Op. Cit., hal. 15

${ }^{67}$ al-Imam Fiqh Ibn Yahya al-Din Abi Zakaria Yahya Ibn Syarif al-Nawawi al-Damisyqy, (1971),al-Azkar al-Nuriyyah, Damaskus, hal. 4 
personalitas yang memberikan manfaatnya yang banyak kepada seorang muslim. Syukur dalam kajian sufi mempunyai makna esoterik intuitif. Mensifati sifat syukur dengan mengembalikan makna yang dituju yaitu al-syakur (Allah) sebagai pemberi merupakan jalan rohani dalam membersihkan diri (tadhkiyah al-nafs) daripada sifat tamak, loba dan zalim serta dapat pula digunakan dalam mendekatkan diri (taqarrub) pada Tuhan. mutma'innah merupakan kajian kondisi rohani yang pembahasannya meliputi kedalaman rohani sufi. Mutma'innah pada prinsipnya adalah kondisi rohani yang tenteram dan tenang sebagai manifestasi daripada ketaqwaan dan kesalehan seseorang kepada Tuhannya. Allah menamakan diri-Nya al-Syakir dan al-Syakur dan juga menamakan orang yang bersyukur itu dengan dua nama ini. Dalam hal ini Allah mensifatkan manusia yang bersyukur dengan sifat-Nya dan memberikan nama kepada mereka dengan nama-Nya. Allah memberikan anugerah dan kurnia kepada orang-orang yang bersyukur, tetapi sedikit sekali di antara manusia (hamba-hamba Tuhan) yang bersyukur kepada-Nya. ${ }^{68}$

Secara psikologi, perasaan bersyukur akan memberikan kepuasan kepada diri sendiri yang dapat menghilangkan perasaan resah sekiranya gagal memperoleh sesuatu yang dihajati. Dalam konteks ini, manusia diajarkan supaya melihat orang yang belum bernasib baik dan masih dalam merugi, sehingga hidup menjadi tenang dan tenteram. ${ }^{69}$

Al-Qur'an mengingatkan seorang muslim agar senantiasa bersyukur atas karunia dan rezeki yang diperoleh terlepas daripada marabahaya dan dianugerahkannya nikmat kehidupan. ${ }^{70}$ Larangan Allah SWT kepada manusia yang takabbur dengan kelebihan diri, karena semua itu pemberian Allah dan akan kembali kepada-Nya. ${ }^{71}$ Bentuk daripada bersyukur itu, semestinya diiringi dengan salat, infak, dan sedekah. ${ }^{72}$ Kesan psikologi manusia yang bersyukur kepada nikmat dan pemberian Allah, adalah rasa ketenangan, kedamaian, keselesaan dan kesehatan mental.

Mutma'innah hadir pada saat berlaku kecemasan, kesusahan dan kegelisahan menepi daripada diri seorang sufi dan dia tetap tenteram dan tenang selama mutma'innah menetap dalam hatinya. Dalam tasawuf, muthma'innah dinisbahkan

68 Ibn al-Qayyim al-Jauziyyah, Madarij, Op.Cit., hal.236

69 Feldman RS, (1996), Understanding Psychology, New York, MC.Graw Hill, hal. 106

70 Lihat QS. Al-Zumar:49

71 Lihat QS. Al-Hadid:23

72 Lihat QS. Al-Kautsar:2 
kepada al-ahwal yaitu kondisi psikologis yang tenteram dengan mengingat Allah (dzikr ila Allah), mengerjakan amal shaleh dan bertaqarrub (mendekatkan) kepadaNya. Menurut 'Abdullah al-Ansari, muthma'innah dapat dibagi kepada beberapa bagian yaitu: Pertama, muthma'innah hati karena menyebut asma' Allah. Ini merupakan muthma'innah orang yang takut (khauf) beralih kepada harapan dari kegelisahan kepada hukum dan dari cobaan kepada pahala. Kedua, muthma'innah yaitu ketika mencapai tujuan pengungkapan hakikat, saat merindukan janji dan saat berpisah untuk berkumpul kembali. Ketiga, muthma'innah karena menyaksikan kasih sayang Allah, muthma'innah kebersamaan menuju keberkekalan dan muthma'innah kedudukan menuju cahaya azali. ${ }^{73}$

Dalam psikoterapi sufistik, syukur dan mutma'innah dapat berfungsi dalam metode takhalli, tajalli dan tahalli bagi kehidupan sufi. Pengosongan diri daripada sifat keburukan pekerti berupa seperti; tamak, benci, sombong, pesimis dan dengki. Kemudian diisi dengan sifat syukur dan mutma'innah, serta dapat pula mempertahankan nilai tersebut serupa sifat syukur dan mutma'innah menjadi pencegah (preventive), perubatan (curative) dan pembinaan (constructive) diri menjadi insan yang bebas daripada gangguan kejiwaan, kesusahan dan kecemasan. Psikoterapi syukur dan mutma'innah pada hakikatnya adalah merawat jiwa seorang sufi menjadi insan yang memiliki jati diri dan kesehatan mental yang sempurna.

Ajaran tentang syukur dan mutmäinnah dalam sufi/tasawuf merupakan komponen pemulihan. Seseorang pasien yang bersyukur niscara akan tenang jiwa, sihat mentalnya, dan mendapati dirinya dalam kebahagiaan. Seorang terapis mengarahkan pasien, agar terbiasa mensyukuri nikmat yang sedikit, sehingganya yang sedikit dirasakan sebagai nikmat yang banyak yang dapat disyukuri. Kesan yang demikian, seorang pasien dapat melahirkan ketenteraman dan kesehatan mental dalam jiwa.

\section{J. Penutup}

Psikoterapi Islam dengan menggunakan metodologi sufistik adalah wacana baru bagi menumbuhkembangkan kesehatan mental Islam. Psiko spiritual Islam merupakan kerangka psikologi dalam mengkaji kejiwaan Islam, bagaimana ia wujud dan memiliki eksistensi dalam kehidupan manusia.

73 Syaikhul Islam Abdullah al-Ansari al-Harawi, (1988), Kitab Manazil al-Sairin, Beirut, Darel Kutub Ilmiyyah, hal. 85-86 
Kesehatan mental adalah dambaan setiap individu, ia tidak hadir tanpa usaha yang maksimal. Banyak cara dan metode yang dicoba dan digunakan oleh para pakar kesehatan mental. Karena itu bermunculanlah teori-teori kesehatan mental dan psikoterapi. Kita tidak akan melupakan Sigmund Freud dengan Psikoanalisisnya, Abraham H. Maslow dengan Humanistiknya, John Broadus Watson dengan Behavioristiknya, dan Vicktor E. Frankl dengan Logoterapinya. Mereka ini memiliki memiliki teoi yang berbeda dalam perwujudan kesehatan mental dan penerapan teori.

Tasawuf atau sufistik yang lebih kepada intuisi, banyak menggunakan metodologi bagi menumbuhkembangkan kepribadian dan kesehatan mental. Para ahli tasawuf, senang bertaqarrub kepada Allah dengan bertaubat, bersabar, bertawakkal, berzuhud, bermahabbah, bersyukur, redha, dan bermuth'mainnah. Pada mulanya perilaku ini adalah perilaku ketaatan dan kesalehan seorang sufi untuk selalu ingin dekat dengan Allah dan mereka merasakan ketenangan, kebahagiaan, dan kesehatan mental. Setelah ditela'ah dan diteliti kesehatan mental pengamal-pengamal tasawuf tersebut, ternyata jauh lebih baik dan hidup dalam ketenangan dengan merasa dekat kepada Allah. Ketertarikan ini, membuat penulis ingin menuangkan kajian ini lebih antusias untuk dipahami dan diamalkan oleh para terapis Islam, psikolog Islam, dan konselor Islam.

\section{DAFTAR PUSTAKA}

Adam, Ahmad Masri dan Nadhif Jama'. 1996. The Way to Happiness. Terj. Muhammad Hashim. Jakarta: Lentera.

al- Jauziyyah, Ibn Al-Qayyim. 1998. Madarij al-Salikin Bain Manazil Iyyaka Na’bud wa Iyyaka Nasta'in, terj. Kathur Sukardi. Jakarta: Pustaka Al-Kautsar.

al-Damisyqy, al-Imam Fiqh Ibn Yahya al-Din Abi Zakaria Yahya Ibn Syarif al-Nawawi. 1971. al-Azkar al-Nuriyyah. Damaskus.

Al-Ghazali, Imam. 1994. Tahzib al-Akhlaq wa Muallajat Amradh al-Qulub, terj. Muhammad Baqir. Bandung: Karisma.

al-Ghazali, Imam. 1996. Al-Mukasyafat al-Qulub. Terj. Ahmad Sunarji. Bandung: Husaini.

al-Halabi, Qassim. al-Sair wa al-Suluk Ila Malik al-Muluk. Jakarta: Naskah Perpustakaan Nasional (Musium Pusat), No.CCCTX IV. 
al-Harawi, Syaikhul Islam Abdullah al-Ansari. 1988. Kitab Manazil al-Sairin. Beirut: Darel Kutub Ilmiyyah.

al-Hujwiri, Ali Ibn Utsman. 1993. The Kasyful Mahjub: the Oldest Persian Treatist and Sufi. Terj. Suwarjo Matori. Bandung: Mizan.

al-Jauziyyah, Ibn al-Qayyim. 1998. Thariq al-Hijratain. terj. Kathur Sukardi. Jakarta: Pustaka al-Kautsar.

al-Kalabadzi, Ibn Abi Ishaq Muhammad Ibn Ibrahim Ya'kub al-Bukhari. 1998. alTa’arruf li Madhhab Ahl al-Tasawuf, Terj. Rahmani Astuti. Bandung: Mizan. al-Naisaburi, Imam al-Qusyairi. 1999. Al-Risalah Qusyairiyah. terj. Lukman Hakim. Surabaya: Risalah Gusti.

al-Syafi, Syekh Muhammad Mahdi. 1996. Al-hubb Ilahi fi Adliyyah Ahl Bait. Terj. Ikhlas. Bandung: Pustaka Hidayah.

al-Zain, Samih 'Atif. 1993. al-Syufiyyah fi Nazri al-Islam. Beirut: Maktabah alDiratsah.

An-Naraqy, Muhammad Mahdi Ibn Abi Zar. 1993. Jami' Al-Sa'adah. Terj. M. Hasim. Bandung: Mizan.

Darajat, Zakiah. 1989. Puasa Meningkatkan Kesihatan Mental. Jakarta: Ruhama.

Effendi, Johan. 1991. Tasawuf Al-Qur'an Tentang Perkembangan Jiwa Manusia, dalam, Ulumul Qur'an, no. 8 Vol Î.

Feldman RS. 1996. Understanding Psychology. New York: MC.Graw Hill.

Hashim Al-Rasuli al-Mahallati, Sayyid. 1994. Iqaba al-Dhunub. terj. Bahruddin Fanani. Bandung: Pustaka Hidayah.

Hawwa, Sayyid. 1998. Tarbiyah al-Ruhaniyyah, terj. Khairul Rafie. Bandung: Mizan. Izutsu, Toshihiko. 1966. Ethico Religious Concept in the Qur'an. Canada: Mc Gill University.

Jaya, Yahya. 1992. Peranan Taubat dan Maaf dalam Kesihatan Mental. Jakarta: Ruhama.

Jaya, Yahya. 1994. Spiritualisasi Islam Dalam Menumbuhkembangkan Kepribadian dan Kesehatan Mental. Jakarta: Ruhama. 
Khaja, Khan .Salib 1987. Studies In Tasawuf. Terj. Ahmad Nasir. Jakarta: Rajawali Pers.

Lari, Sayyid Mujtaba Musavi. 1990. Youth and Moral. Quin: Islamic Culture Development Office.

Nurdin, KH. Muslim. 1993. Moral dan Kognisi Islam. Bandung: al-Fabeta.

Proyek Pembinaan PTA. 1981. Pengantar Ilmu Tasawuf. Sumut: IAIN.

Quzwain, M. Chatib. Mengenal Allah: Suatu Pengajian Mengenai Ajaran Tasawuf Syaikh Abdul Samad Al-Palimbani. Jakarta: Bulan Bintang. 